\title{
FELICIDADE E TRABALHO NA PERCEPÇÃO DOS PROFESSORES DO ENSINO SUPERIOR: REVISÃO INTEGRATIVA
}

\author{
Martha Eliana Waltermann (D1, Maria Isabel Morgan Martins iD2 e Dóris Gedrat (iD)
}

\section{Resumo}

A felicidade é entendida com a sensação de equilíbrio entre três estruturas essenciais do ser humano: corpo, psiquismo e espírito. É também denominada de bem-estar subjetivo. Trabalho é a ferramenta que permite ao homem realizar a sua felicidade, oferecendo-lhe condições financeiras para seu sustento e a possibilidade de desenvolver algo que lhe dê prazer. O professor universitário é o profissional que deve dominar os conteúdos que ministra, com capacidade de refletir sobre ele e pensar criticamente o processo de ensino-aprendizagem. Precisa estar em constante capacitação e atualizado em relação à bibliografia utilizada e às metodologias de aprendizagem cada vez mais presentes. Nossa pesquisa objetivou conhecer a influência do trabalho na percepção dos professores universitários sobre felicidade e sofrimento no trabalho. Como método, utilizamos a revisão integrativa da literatura, com busca realizada nas bases de dados LILACS, BVS e SCIELO, com os descritores felicidade, trabalho e professor universitário, de artigos publicados de 2016 a 2020. Foram encontrados 83 artigos, sendo selecionados 10 que se adequaram aos critérios de inclusão. Emergiram três categorias: felicidade no trabalho do professor universitário, sofrimento no trabalho do professor universitário e prejuízo à saúde física e à saúde psíquica do professor universitário. Sofrimento e doenças biopsicossociais foram apontados como gerando impacto na qualidade de vida do docente e nas organizações educacionais. Sugere-se realizar novos estudos a fim de identificar e contextualizar as questões da felicidade no trabalho e seus prováveis impactos no comportamento do indivíduo na organização e na qualidade de vida.

Palavras-chave: Felicidade; Trabalho; Professor universitário.

\section{HAPPINESS AND WORK IN THE PERCEPTION OF HIGHER EDUCATION TEACHERS: INTEGRATIVE REVIEW}

\section{Abstract}

Happiness is understood as the sensation of balance between three essential structures of the human being: body, psyche and spirit. It is also called

\footnotetext{
${ }^{1}$ Mestranda em Promoção da Saúde pela Universidade Luterana do Brasil (ULBRA). Docente do Curso de Enfermagem da ULBRA.

${ }^{2}$ Doutora em Ciências Biológicas pela Universidade Federal do Rio Grande do Sul (UFRGS). Professora do Programa de Pós-Graduação em Promoção da Saúde, da Universidade Luterana do Brasil (ULBRA).

${ }^{3}$ Doutora em Linguística Aplicada pela Pontifícia Universidade Católica do Rio Grande do Sul (PUCRS). Professora do Programa de Pós-Graduação em Promoção da Saúde, da Universidade Luterana do Brasil (ULBRA).
}

Perspectivas em Diálogo, Naviraí, v. 09, n. 19, p. 175-194, jan./abr. 2022. 
subjective well-being. Work is the tool that allows one to achieve happiness, financial conditions for livelihood and the developing of something pleasant. The university professor must master the content, with the ability to reflect on it and think critically about the teaching-learning process. Constant training and updated in relation to the bibliography used and the learning methodologies increasingly present is necessary. The objective of our research is to know the influence of work on university teachers' perception of happiness and suffering at work. The methodology is integrative review of the literature, for which a search was carried out in the databases LILACS, BVS and SCIELO, with the descriptors happiness, work and university professor, in articles published from 2016 to 2020. 83 articles were found, of which 10 were selected that met the inclusion criteria. Three categories emerged: happiness in the work of the university professor, suffering in the work of the university professor and impairment of the physical and psychological health of the university professor. Suffering and biopsychosocial diseases were identified as having an impact on the quality of life of teachers and educational organizations. It is suggested to carry out further studies in order to identify and contextualize the issues of happiness at work and its likely impacts on the individual's behavior in the organization and quality of life.

Keywords: Happiness; Work; Higher Education Teacher.

\section{Introdução}

São muitos os sinônimos empregados para conceituar e caracterizar a felicidade. Estudos realizados nos últimos anos buscam definir seu significado e indicar ações capazes de potencializá-la. Apresentam questões ligadas ao prazer, à felicidade no trabalho e ao bem-estar (SENDER; FLECK, 2017). A felicidade é considerada uma emoção básica, representada por um estado emocional positivo, com sentimentos de bem-estar e de prazer, relacionados à percepção de sucesso e à compreensão coerente e lúcida do mundo. É um fenômeno subjetivo dependente mais de traços psicológicos e socioculturais, do que de condições externamente estabelecidas (FERRAZ; TAVARES; ZILBERMAN, 2007).

Estudos apontam que a felicidade é a sensação de equilíbrio entre as três estruturas essenciais do ser humano: corpo, psiquismo e espírito (ALBUQUERQUE; TRÓCCOLI, 2004; RIBEIRO, 2015; MENDONÇA, 2016). Segundo Houaiss (2004), felicidade é um estado de consciência plenamente satisfeita e sensação de bem-estar.

Por sua vez, o trabalho vem sendo apontado como um dos valores fundamentais do ser humano, exercendo importante papel no desenvolvimento da sua autorrealização, de suas emoções e de sua sociabilidade (NEVES et al., 2018). Ele contribui para o desenvolvimento da identidade dos sujeitos, proporciona-Ihes renda e sustento, permite atingir metas e objetivos de vida, e oportuniza demonstrar suas ações, iniciativas e habilidades. Considerar os funcionários como principal ativo nas organizações é uma medida inteligente, 
pois isso propicia tratamento respeitoso e valorização profissional, em contrapartida, motiva os trabalhadores a se envolverem e a se comprometerem mais com o trabalho (VASCONCELOS, 2004).

Está-se considerando, aqui, a visão marxista sobre o trabalho (MARX, 1985) e suas dicotomias. Se, por um lado, o trabalho identifica homens e mulheres enquanto humanos, não selvagens, revelando seu sentido humanizador, por outro, com a acumulação de capital, a classe trabalhadora ficou sem acesso aos meios de produção, além de ter de vender sua força de trabalho a quem possui esses meios. Assim, de humanizador, com o capitalismo o trabalho passa a ser comercializador. Nessa relação, o trabalhador é o produto que gera lucro para outrem. Essa dicotomia reflete-se nos dias de hoje, quando as pessoas procuram realização no trabalho, deparando-se com seu sentido desumanizador, originado com o capitalismo.

Quando o objetivo é ser feliz, tudo o que se faz tem o propósito de alcançálo. É grande a relação entre felicidade e trabalho. Nas organizações nas quais os trabalhadores são considerados mais felizes ocorre mais lucratividade, produtividade, menor absenteísmo e rotatividade. O trabalho é, portanto, uma ferramenta que permite ao homem realizar-se pessoalmente, sendo, também, um facilitador para alcançar a felicidade. Nessa perspectiva, o trabalho é de fundamental relevância para a realização humana, sendo possível obter felicidade a partir dele, embora sejam necessárias transformações nas atuais condições conflituosas do mundo do trabalho (MENDONÇA; JUNGES; PINHEIRO, 2016).

O trabalho docente, por sua vez é uma atividade complexa, que envolve aspectos relacionais, pedagógicos, formativos e profissionais. É desenvolvido por professores das diversas áreas de conhecimento e compreende ensino, aprendizagem de conhecimentos e desenvolvimento de habilidades para ensinar. Envolve a relação dinâmica e indissociável entre professor, aluno e conteúdo. O docente não se restringe às atividades da sala de aula, da pesquisa e administrativas, uma vez que os professores têm a responsabilidade de desenvolver atividades complementares e simultâneas (SCREMIN; ISAIA, 2013).

Segundo Zabalza (2004), o professor universitário atua em três dimensões: pessoal, profissional e administrativa. A dimensão pessoal é aquela que interfere no mundo da docência a partir de alguns dados como a satisfação na atividade laboral e outras situações de cunho pessoal; a profissional é a que caracteriza os componentes essenciais que definem a sua profissão docente; e a administrativa é aquela que envolve questões contratuais, salariais, de carreira, condições de trabalho e outros afazeres característicos do exercício profissional. Essas dimensões não são excludentes entre si. Assim, os professores universitários devem ser bons formadores, bons cientistas e bons administradores (ZABALZA, 2004).

O professor de Instituições de Ensino Superior (IES) é um profissional que necessita estar em desenvolvimento permanente e com a capacidade de refletir sobre a sua formação profissional. Esta não se restringe somente a 
pensar e discutir a organização do ensino, seu contexto e seus desdobramentos. Como parte do desenvolvimento profissional do professor, sua formação deve ser contínua e sistemática, a fim de atender às necessidades psicológicas, sociais, pessoais e profissionais do cenário no qual atua (GONÇALVES, 2008). Além da docência, o professor universitário é atuante na pesquisa e na extensão, o que exige produção e publicação de resultados científicos e a utilização destes em projetos que envolvam a comunidade. Portanto, a atividade docente está exposta a altas exigências de trabalho e a ambientes conflituosos, podendo afetar a percepção de felicidade e a saúde dos professores. Assim, o objetivo deste estudo é conhecer a influência do trabalho docente na percepção dos professores universitários sobre felicidade e sofrimento no trabalho.

\section{Metodologia}

Esta pesquisa é uma revisão integrativa da literatura cujo propósito é ter entendimento de um determinado assunto, baseando-se em estudos anteriores. Proporciona a síntese do conhecimento e a incorporação dos resultados de estudos significativos (MENDES; SILVEIRA; GALVÃO, 2008). Envolve a definição do problema de pesquisa, a identificação das informações necessárias, a busca de estudos na literatura e sua avaliação crítica. Fundamenta-se em seis fases distintas: elaboração da pergunta norteadora; busca ou amostragem na literatura; coleta de dados; análise crítica dos estudos incluídos; discussão dos resultados e apresentação da revisão integrativa. Permite a inclusão de estudos experimentais e não experimentais para uma compreensão completa do fenômeno analisado (GALVÃO; SAWADA; TREVIZAN, 2004).

Assim, foi realizada uma busca na literatura científica nas bases de dados: LILACS (Literatura Latino-Americana e do Caribe em Ciências da Saúde), BVS (Biblioteca Virtual em Saúde) e SCIELO (Scientific Electronic Library Online), utilizando-se como descritores: felicidade, trabalho docente e professor de ensino superior, com o operador booleanos AND. A pergunta norteadora deste estudo foi "Qual a influência do trabalho docente na percepção dos professores universitários sobre felicidade e sofrimento no trabalho?".

Como critérios de inclusão foram selecionadas publicações científicas, editadas em português, que atendessem aos objetivos deste estudo, publicados nos últimos cinco anos, ou seja, no período de 2016 a 2020, com textos na íntegra e disponíveis por meio eletrônico. Como critérios de exclusão foram eliminadas publicações de revisões de literatura, livros, monografias, teses, anais, relatos de eventos científicos e textos incompletos.

\section{Processo de refinamento da busca}

Foram encontrados 83 artigos nas bases de dados após a pesquisa com os descritores. Destes, 73 foram excluídos, pois os mesmos não atendiam aos critérios de inclusão. Assim, foram selecionados 10 artigos que se adequaram aos critérios de inclusão definidos (Figura 1). 
Figura 1 - Sínteses dos artigos que atenderam aos critérios de inclusão.

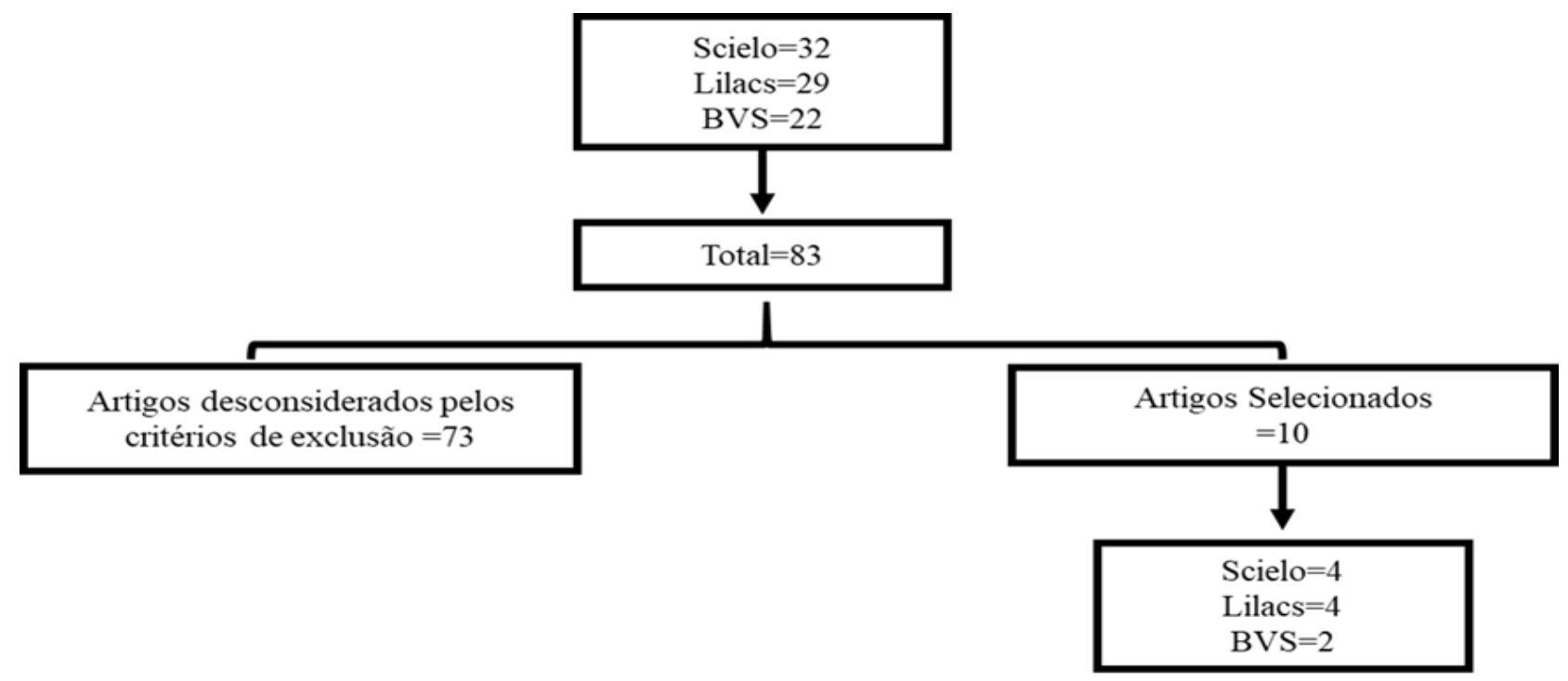

Fonte: Autoras (2021).

Para a análise e posterior síntese dos artigos que atenderam aos critérios de inclusão, elaborou-se uma planilha para coleta de dados informando o título do artigo, autores, ano de publicação, metodologia, objetivo e resultados (Quadro 1).

Quadro 1 - Sumarização dos estudos

\begin{tabular}{|c|c|c|c|c|c|}
\hline $\begin{array}{c}\text { Autor(es)/ } \\
\text { Ano }\end{array}$ & $\mathrm{N}$ & Título & Método & Objetivo & Resultados \\
\hline $\begin{array}{c}\text { RIBEIRO, } \\
\text { ADS; } \\
\text { SILVA, N, } \\
2020\end{array}$ & E1 & $\begin{array}{l}\text { Sentido e } \\
\text { significado } \\
\text { de felicidade } \\
\text { no trabalho } \\
\text { para } \\
\text { professores }\end{array}$ & $\begin{array}{l}\text { O estudo é misto: } \\
\text { quantitativo, com } \\
\text { aplicação de } \\
\text { instrumento on- } \\
\text { line; } 2 \text { qualitativos, } \\
\text { sendo elaborado } \\
\text { uma entrevista } \\
\text { semiestruturado, } \\
\text { com perguntas } \\
\text { abertas. }\end{array}$ & $\begin{array}{l}\text { Compreender } \\
\text { como se } \\
\text { constituem as } \\
\text { relações entre } \\
\text { sentidos e } \\
\text { significados do } \\
\text { trabalho e as } \\
\text { possíveis } \\
\text { consequências } \\
\text { à construção } \\
\text { da felicidade } \\
\text { no trabalho } \\
\text { dos } \\
\text { professores. }\end{array}$ & $\begin{array}{l}\text { Se estabeleceu uma } \\
\text { relação entre o grau de } \\
\text { importância do trabalho na } \\
\text { vida dos professores, o } \\
\text { orgulho pela profissão e a } \\
\text { relevância das condições } \\
\text { materiais para a realização } \\
\text { do trabalho. }\end{array}$ \\
\hline $\begin{array}{l}\text { VIVIAN, C; } \\
\text { TRINDADE, } \\
\text { LL; } \\
\text { VENDRUSC } \\
\text { OLO, C, } \\
2020\end{array}$ & E2 & $\begin{array}{l}\text { Prazer e } \\
\text { sofrimento } \\
\text { docente: } \\
\text { estudo na } \\
\text { pós- } \\
\text { graduação } \\
\text { stricto sensu }\end{array}$ & $\begin{array}{l}\text { O estudo é } \\
\text { descritivo, } \\
\text { quantitativo- } \\
\text { qualitativo. } \\
\text { Participaram } 47 \\
\text { professores de sete } \\
\text { programas do } \\
\text { stricto sensu. } \\
\text { Instrumentos: } \\
\text { Inventário sobre } \\
\text { Trabalho e Riscos } \\
\text { de Adoecimento e } \\
\text { entrevista. }\end{array}$ & $\begin{array}{l}\text { Identificar as } \\
\text { situações } \\
\text { geradoras de } \\
\text { estímulo e } \\
\text { dificuldade no } \\
\text { processo } \\
\text { docente da } \\
\text { pós-graduação } \\
\text { stricto sensu. }\end{array}$ & $\begin{array}{l}\text { Os processos de prazer e } \\
\text { sofrimento docentes foram } \\
\text { influenciados por: tempo } \\
\text { de formação profissional, } \\
\text { titulação, horas de jornada } \\
\text { laboral e atuação como } \\
\text { coordenador de curso. }\end{array}$ \\
\hline
\end{tabular}




\begin{tabular}{|c|c|c|c|c|c|}
\hline $\begin{array}{l}\text { BROCH, C; } \\
\text { BOTH, J; } \\
\text { TEIXEIRA, } \\
\text { FC; PIZANI, } \\
\text { J; RINALDI, } \\
\text { IPB, 2020. }\end{array}$ & E3 & $\begin{array}{l}\text { A satisfação } \\
\text { no trabalho } \\
\text { docente em } \\
\text { educação } \\
\text { física: um } \\
\text { diagnóstico } \\
\text { do perfil de } \\
\text { professores } \\
\text { universitário } \\
\text { s }\end{array}$ & $\begin{array}{l}\text { O estudo é } \\
\text { descritivo, } \\
\text { quantitativo e } \\
\text { transversal. } \\
\text { Participaram } \\
99 \text { docentes: } \\
\text { Educação Física, de } \\
\text { instituições } \\
\text { públicas e privadas } \\
\text { do Paraná. } \\
\text { Instrumentos: } \\
\text { questionário } \\
\text { sociodemográfico e } \\
\text { Qualidade de Vida } \\
\text { no Trabalho. }\end{array}$ & $\begin{array}{l}\text { Verificar os } \\
\text { diferentes } \\
\text { perfis de } \\
\text { docentes } \\
\text { universitários } \\
\text { de Educação } \\
\text { Física, } \\
\text { considerando } \\
\text { à satisfação } \\
\text { no trabalho. }\end{array}$ & $\begin{array}{l}\text { Aspectos } \\
\text { sociodemográficos e } \\
\text { profissionais são fatores } \\
\text { intervenientes na } \\
\text { satisfação com o trabalho } \\
\text { docente. }\end{array}$ \\
\hline $\begin{array}{l}\text { PENA, L; } \\
\text { REMOALDO } \\
\text {, P, 2019. }\end{array}$ & E4 & $\begin{array}{l}\text { Psicodinâmic } \\
\text { a do } \\
\text { Trabalho: } \\
\text { um estudo } \\
\text { sobre o } \\
\text { prazer e o } \\
\text { sofrimento } \\
\text { no trabalho } \\
\text { docente na } \\
\text { Universidade } \\
\text { Óscar Ribas }\end{array}$ & $\begin{array}{l}\text { O estudo é } \\
\text { descritivo, } \\
\text { quantitativo. } \\
\text { Participaram } 56 \\
\text { professores } \\
\text { docentes da } \\
\text { Universidade Óscar } \\
\text { Ribas (UOR). } \\
\text { Instrumentos: } \\
\text { questionário } \\
\text { sociodemográfico, } \\
\text { escala de prazer e } \\
\text { sofrimento no } \\
\text { trabalho (EPST), } \\
\text { escala de sintomas } \\
\text { relacionados com o } \\
\text { trabalho (ESRT). }\end{array}$ & $\begin{array}{l}\text { Analisar os } \\
\text { sintomas } \\
\text { biopsicossociai } \\
\text { s e os } \\
\text { sentimentos } \\
\text { de prazer e/ou } \\
\text { de sofrimento } \\
\text { relacionados } \\
\text { com o } \\
\text { trabalho } \\
\text { docente. }\end{array}$ & $\begin{array}{l}\text { A identificação com as } \\
\text { tarefas, a liberdade para } \\
\text { falar no trabalho e a } \\
\text { solidariedade entre colegas } \\
\text { são os principais } \\
\text { reveladores de prazer. }\end{array}$ \\
\hline $\begin{array}{c}\text { TUNDIS, } \\
\text { AGO; } \\
\text { MONTEIRO, } \\
\text { JK, } 2018\end{array}$ & E5 & $\begin{array}{l}\text { Ensino } \\
\text { superior e } \\
\text { adoecimento } \\
\text { docente: um } \\
\text { estudo em } \\
\text { uma } \\
\text { universidade } \\
\text { pública. }\end{array}$ & $\begin{array}{l}\text { Estudo é descritivo, } \\
\text { quantitativo. } \\
\text { Participaram } 52 \\
\text { docentes, } \\
\text { universidade } \\
\text { pública da região } \\
\text { amazônica. } \\
\text { Instrumentos: } \\
\text { questionário } \\
\text { sociodemográfico e } \\
\text { laboral, } \\
\text { Inventário sobre } \\
\text { Trabalho e Risco de } \\
\text { Adoecimento. }\end{array}$ & $\begin{array}{l}\text { Identificar } \\
\text { fatores críticos } \\
\text { do contexto } \\
\text { laboral de } \\
\text { docentes do } \\
\text { ensino } \\
\text { superior } \\
\text { público } \\
\text { associados a } \\
\text { risco à saúde } \\
\text { mental }\end{array}$ & $\begin{array}{l}\text { O contexto do trabalho foi } \\
\text { avaliado como crítico. } \\
\text { Fatores relacionados ao } \\
\text { prazer foram satisfatórios } \\
\text { para a realização } \\
\text { profissional. Em relação ao } \\
\text { sofrimento foi pontuado o } \\
\text { esgotamento profissional } \\
\text { como o mais crítico. }\end{array}$ \\
\hline $\begin{array}{l}\text { OLIVEIRA, } \\
\text { IB; } \\
\text { RIBEIRO, } \\
\text { JAB; } \\
\text { AFONSO, } \\
\text { MA, 2018 }\end{array}$ & E6 & $\begin{array}{l}\text { Satisfação } \\
\text { com a } \\
\text { profissão: } \\
\text { um estudo } \\
\text { com } \\
\text { professores } \\
\text { de Educação } \\
\text { Física }\end{array}$ & $\begin{array}{l}\text { Estudo é descritivo } \\
\text { e qualitativa. } \\
\text { Participaram } 20 \\
\text { professores de } 2 \\
\text { campus do } \\
\text { Instituto Federal do } \\
\text { Sul (IFSUL). } \\
\text { Instrumento: } \\
\text { questionário com } \\
\text { duas partes o perfil } \\
\text { docente, satisfação } \\
\text { docente, indicando } \\
\text { satisfação no } \\
\text { exercício da } \\
\text { profissão e no } \\
\text { trabalho } \\
\text { pedagógico. }\end{array}$ & $\begin{array}{l}\text { Verificar a } \\
\text { satisfação } \\
\text { profissional } \\
\text { dos } \\
\text { professores da } \\
\text { Escola Federal } \\
\text { (EF) e da } \\
\text { Rede de } \\
\text { Educação } \\
\text { Profissional } \\
\text { Científica e } \\
\text { Tecnológica } \\
\text { (RFEPCT) na } \\
\text { cidade de } \\
\text { Pelotas/RS, do } \\
\text { IFSUL. }\end{array}$ & $\begin{array}{l}\text { Os principais sentimentos } \\
\text { de satisfação foram a } \\
\text { relação com o aluno e o } \\
\text { seu reconhecimento por } \\
\text { parte destes, além da } \\
\text { realização pessoal e } \\
\text { profissional de ser } \\
\text { professor. Os sentimentos } \\
\text { de insatisfação foram a } \\
\text { pouca valorização e o } \\
\text { reconhecimento da } \\
\text { profissão e da área por } \\
\text { outros membros da Escola } \\
\text { Federal e esferas gestoras } \\
\text { da educação. }\end{array}$ \\
\hline
\end{tabular}




\begin{tabular}{|c|c|c|c|c|c|}
\hline $\begin{array}{c}\text { AMARAL, } \\
\text { GA; } \\
\text { BORGES, } \\
\text { AL; JUIZ, } \\
\text { APM, 2017 }\end{array}$ & E7 & $\begin{array}{l}\text { Organização } \\
\text { do trabalho, } \\
\text { prazer e } \\
\text { sofrimento } \\
\text { de docentes } \\
\text { públicos } \\
\text { federais }\end{array}$ & $\begin{array}{l}\text { O estudo é } \\
\text { descritivo. } \\
\text { Participaram } 5 \\
\text { docentes de um } \\
\text { campus de interior } \\
\text { de uma } \\
\text { Universidade } \\
\text { Pública Federal. } \\
\text { Instrumentos: } \\
\text { entrevistas } \\
\text { semiestruturadas, } \\
\text { fundamentada na } \\
\text { Análise } \\
\text { Psicodinâmica do } \\
\text { Trabalho (APDT). }\end{array}$ & $\begin{array}{l}\text { Compreender } \\
\text { a relação } \\
\text { entre } \\
\text { organização } \\
\text { do trabalho e } \\
\text { as vivências } \\
\text { de prazer e } \\
\text { sofrimento de } \\
\text { docentes de } \\
\text { um campus do } \\
\text { interior de } \\
\text { uma } \\
\text { universidade } \\
\text { federal. }\end{array}$ & $\begin{array}{l}\text { Constatou-se } \\
\text { demonstração de prazer } \\
\text { no trabalho por meio de } \\
\text { atividades de ensino e } \\
\text { pesquisa e do } \\
\text { relacionamento com os } \\
\text { alunos. As vivências de } \\
\text { sofrimento referem-se às } \\
\text { situações de conflitos } \\
\text { interpessoais e à falta de } \\
\text { infraestrutura e sobrecarga } \\
\text { no trabalho. }\end{array}$ \\
\hline $\begin{array}{c}\text { SOUTO, } \\
\text { BLC; BECK, } \\
\text { CLC; } \\
\text { TRINDADE, } \\
\text { LR; SILVA, } \\
\text { RM; } \\
\text { BACKES, } \\
\text { DS; } \\
\text { BASTOS, } \\
\text { RA, 2017 }\end{array}$ & E8 & $\begin{array}{l}\text { O trabalho } \\
\text { docente em } \\
\text { pós- } \\
\text { graduação: } \\
\text { prazer e } \\
\text { sofrimento }\end{array}$ & $\begin{array}{l}\text { Estudo descritivo, } \\
\text { exploratório e } \\
\text { qualitativo. } \\
\text { Participaram } 6 \\
\text { docentes de } \\
\text { programas de pós- } \\
\text { graduação em nível } \\
\text { de mestrado de } \\
\text { uma Universidade } \\
\text { Federal. } \\
\text { Instrumentos: } \\
\text { entrevista } \\
\text { semiestruturada, } \\
\text { realizada análise } \\
\text { de conteúdo. }\end{array}$ & $\begin{array}{l}\text { Descrever os } \\
\text { sentimentos } \\
\text { de prazer e } \\
\text { sofrimento no } \\
\text { trabalho } \\
\text { docente em } \\
\text { pós-graduação } \\
\text { na perspectiva } \\
\text { dos docentes. }\end{array}$ & $\begin{array}{l}\text { A construção da identidade } \\
\text { docente e a visibilidade e } \\
\text { reconhecimento são } \\
\text { importantes fatores na } \\
\text { profissão e que o prazer } \\
\text { no trabalho é possível } \\
\text { quando se faz o que se } \\
\text { gosta. }\end{array}$ \\
\hline $\begin{array}{c}\text { SILVEIRA, } \\
\text { RCP; } \\
\text { RIBEIRO, } \\
\text { IKS; } \\
\text { TEIXEIRA, } \\
\text { LN; } \\
\text { TEIXEIRA, } \\
\text { GS; MELO, } \\
\text { JMA; DIA, } \\
\text { SF, } 2017\end{array}$ & E9 & $\begin{array}{l}\text { Bem-estar e } \\
\text { saúde de } \\
\text { docentes em } \\
\text { instituição } \\
\text { pública de } \\
\text { ensino }\end{array}$ & $\begin{array}{l}\text { O estudo é } \\
\text { descritivo, } \\
\text { correlacional, } \\
\text { transversal, } \\
\text { quantitativa. } \\
\text { Participaram } 82 \\
\text { docentes, de uma } \\
\text { instituição de } \\
\text { ensino público. } \\
\text { Instrumentos: } \\
\text { Escala de Faces de } \\
\text { Andrews, Índice de } \\
\text { Bem-estar (WHO- } \\
\text { 5) e Escala de } \\
\text { Bem-estar } \\
\text { Psicológico (EBEP). }\end{array}$ & $\begin{array}{l}\text { Identificar o } \\
\text { bem-estar no } \\
\text { trabalho e as } \\
\text { alterações de } \\
\text { saúde dos } \\
\text { docentes de } \\
\text { uma } \\
\text { instituição de } \\
\text { ensino } \\
\text { superior. }\end{array}$ & $\begin{array}{l}\text { Na escala de Faces de } \\
\text { Andrews, a face } \\
\text { predominante foi } 2 \\
\text { "felicidade", com } 39 \% \text {. No } \\
\text { bem-estar, } 64,59 \% \\
\text { apresentaram bem-estar } \\
\text { satisfatório. } 24,7 \% \\
\text { disseram ter se afastado } \\
\text { do trabalho devido à } \\
\text { depressão, síndrome do } \\
\text { pânico, síndrome de } \\
\text { Burnout. }\end{array}$ \\
\hline $\begin{array}{c}\text { DAVOGLIO, } \\
\text { TR; } \\
\text { SPAGNOLO, } \\
\text { C; SANTOS, } \\
\text { BS, } 2017\end{array}$ & $\begin{array}{c}\mathrm{E} 1 \\
0\end{array}$ & $\begin{array}{l}\text { Motivação } \\
\text { para a } \\
\text { permanência } \\
\text { na profissão: } \\
\text { a percepção } \\
\text { dos docentes } \\
\text { universitário } \\
\text { s }\end{array}$ & $\begin{array}{l}\text { Estudo descritivo, } \\
\text { exploratório e } \\
\text { qualitativo. } \\
\text { Participaram } 26 \\
\text { professores da } \\
\text { Educação Superior } \\
\text { públicas e } \\
\text { privadas. } \\
\text { Instrumento: } \\
\text { questionário } \\
\text { autoaplicável } \\
\text { processos } \\
\text { motivacionais } \\
\text { docentes e o perfil } \\
\text { sociodemográfico. }\end{array}$ & $\begin{array}{l}\text { Conhecer os } \\
\text { principais } \\
\text { aspectos que } \\
\text { motivam os } \\
\text { docentes da } \\
\text { Educação } \\
\text { Superior à } \\
\text { permanência } \\
\text { na carreira. }\end{array}$ & $\begin{array}{l}\text { Formaram dez categorias: } \\
\text { relação com alunos; } \\
\text { formação continuada; } \\
\text { gosto/ prazer/satisfação } \\
\text { pela docência; } \\
\text { envolvimento com a } \\
\text { pesquisa científica; salário; } \\
\text { contribuição social da } \\
\text { atuação; ambiente } \\
\text { acadêmico, autonomia, } \\
\text { segurança/estabilidade/pre } \\
\text { stígio e } \\
\text { desafios/compartilhamento } \\
\text { do conhecimento. }\end{array}$ \\
\hline
\end{tabular}

Fonte: Própria autora (2021). 
Estabelecida a categorização dos estudos para a revisão, verificou-se que nove dos dez estudos falavam sobre felicidade no trabalho do professor universitário, sete falavam sobre o sofrimento no trabalho do professor universitário, e, quatro destacaram o prejuízo da saúde física e da saúde psíquica do professor universitário (Quadro 2).

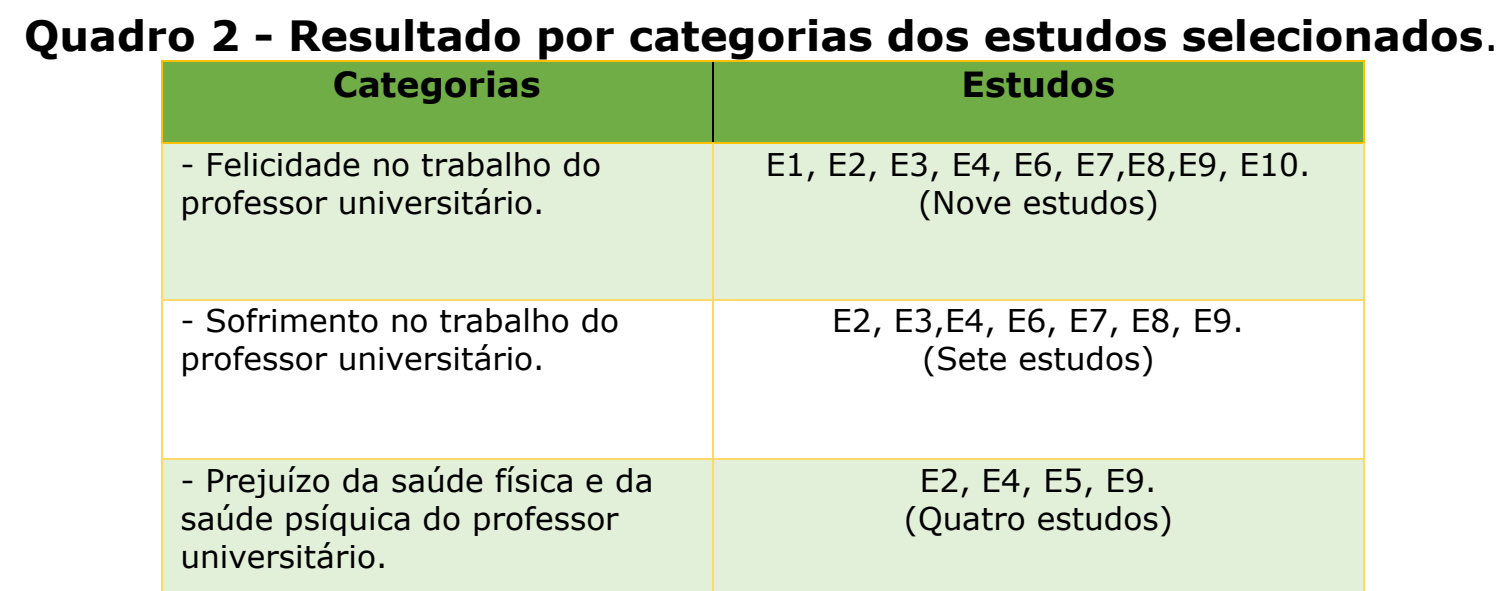

Fonte: Própria autora (2021).

\section{Felicidade no trabalho do professor universitário}

Ribeiro e Silva (2020), no E1, buscaram compreender como se constituem as relações entre sentidos e significados do trabalho e as possíveis consequências da construção da felicidade no trabalho dos professores de graduação e pós-graduação. Fizeram uso de dois instrumentos para o levantamento de dados, com métodos integrados. No Instrumento 1 (quantitativo), obtiveram respostas com percentual maior sobre a felicidade no trabalho, pois os professores referiram ser felizes no trabalho e sentirem orgulho do que fazem por considerá-lo muito importante para a sociedade e para sua própria vida. Esta percepção está relacionada a terem condições materiais, ambiente e equipamentos fornecidos pela organização para realizarem o seu trabalho, estabelecerem adequada comunicação com os demais colaboradores e porque seu trabalho Ihes proporciona sentimentos positivos.

No Instrumento 2 (qualitativo), os professores apontaram relação entre o grau de importância do trabalho na vida dos professores e a relevância das condições materiais para a realização do trabalho. Referiram que o trabalho se tornou central em suas vidas e, portanto, consideram-se felizes na sua atividade profissional e sentem-se orgulhosos de sua profissão. Isso lhes traz uma sensação de paz e harmonia. Apontaram, igualmente, que episódios depressivos, tristeza ou aspectos negativos na vivência do trabalho e na vida não caracterizam ausência de felicidade.

No E2, Vivian, Trindade e Vendruscolo (2020) realizaram pesquisa com docentes da pós-graduação stricto sensu e referiram que há uma linha tênue entre o prazer e o sofrimento no trabalho entre os professores. Consideraram 
que o prazer atribuído ao bem-estar no trabalho relaciona-se à felicidade e apontaram que o reconhecimento profissional é gerador de prazer na esfera organizacional. Além disso, referiram outras questões positivas relacionadas à docência, como a relação docente/discente; a captação de recursos para fomento de pesquisa; o fato de gostarem do que fazem; a produção do conhecimento a partir de pesquisas e publicações. Como fontes de prazer docente está a oportunidade de agregar conhecimentos, fomentar o pensamento crítico e transformar a realidade.

Os entrevistados do referido estudo salientaram que a possibilidade de perceber o crescimento, a transformação, a evolução e a autonomia do aluno ressignifica o exercício profissional do professor e traz prazer. Além disso, apontaram que a dedicação ao stricto sensu diminui a quantidade de horas dos docentes na graduação, possibilitando a dedicação a outras atividades na pósgraduação, como a produção de conhecimentos. Entretanto, a exigência é muito grande, em especial, em relação à realização de pesquisa e publicação dos estudos (VIVIAN; TRINDADE; VENDRUSCOLO, 2020).

Broch et al. (2020), no E3, analisaram diferentes perfis de docentes universitários de Educação Física, classificando-os em três grupos pelas variáveis sociodemográficas, em um contexto de IES públicas e privadas. $O$ estudo buscou compreender os níveis de satisfação no trabalho de acordo com os diferentes perfis dos professores. Os grupos $2(41,4 \%$ da amostra) e 3 (27,3\% da amostra) caracterizaram-se pela satisfação na maioria das dimensões avaliadas: condições de trabalho, autonomia no trabalho, integração social, leis e normas do trabalho, trabalho e espaço total da vida, relevância social do trabalho, avaliação global da satisfação. O Grupo 2 apresentou escores intermediários de satisfação. Embora sejam majoritariamente vinculados a universidades públicas, as quais oferecem melhores condições de remuneração e estabilidade, encontrava-se insatisfeitos com as condições de trabalho no que concerne às condições estruturais, materiais e de equipamento, geralmente precárias.

Já o Grupo 3, composto, predominantemente, por mulheres, com a menor porcentagem de docentes casados, menor tempo de formação, menor período de atuação na IES e menor vínculo com universidades públicas, apresentou os mais elevados escores na dimensão trabalho e espaço total de vida, componente referente ao equilíbrio entre a dedicação profissional e vida pessoal. Estes resultados chamam atenção, pois o grupo mais satisfeito foi aquele com menor estabilidade e segurança financeira na carreira docente.

No E4, Pena e Remoaldo (2019) investigaram docentes de uma universidade de Angola, com a aplicação de duas ferramentas: a primeira é a Escala de Prazer e Sofrimento no Trabalho (EPST), cujos resultados foram obtidos através da aplicação da segunda Escala de Sintomas Relacionados com o Trabalho (ESRT). Dos entrevistados, 54\% manifestaram níveis moderados de prazer e 43\% níveis elevados. Os principais indicadores de prazer foram: identificação com as tarefas, liberdade para falar no trabalho, solidariedade entre os colegas, prazer e orgulho na atividade realizada. 
No E6, os autores verificam a satisfação profissional dos professores de EF da RFEPCT na cidade de Pelotas/RS. Os principais sentimentos de satisfação estiveram relacionados ao reconhecimento de seu trabalho pelos alunos, além da realização pessoal e profissional de ser professor. Este grupo teve prevalência do regime de trabalho de dedicação exclusiva e como consequência, melhora do salário. Isso possibilita não precisarem ter vários empregos, o que melhora sua qualidade de vida. Apresentam índices elevados de satisfação sobre as condições de trabalho, remuneração, jornada de trabalho e relações hierárquicas (OLIVEIRA; RIBEIRO; AFONSO, 2018).

O E7 buscou compreender a relação entre a organização do trabalho e as vivências de prazer e sofrimento de docentes universitários de uma instituição pública. Nos resultados obtidos sobre prazer laboral, houve destaque das atividades de ensino e as relações interpessoais com os alunos, ligadas ao significado do ser professor. Além disso, as atividades de pesquisa das quais participam possibilitou o uso da inteligência prática e o reconhecimento de sua condição de pesquisador (AMARAL; BORGES; JUIZ, 2017).

O E8 buscou descrever os sentimentos de prazer e sofrimento no trabalho do professor de pós-graduação stricto sensu de uma universidade federal. Referiu que o trabalho nunca deve ser considerado neutro em relação à vida dos sujeitos, pois ele favorece a saúde ou a doença por poder gerar prazer ou sofrimento. O reconhecimento de seu trabalho docente potencializa o sentimento de prazer e satisfação gerando pertencimento à profissão e edificando uma identidade. Para o docente enfermeiro, sentimentos de satisfação e prazer, estão relacionados à socialização de seu conhecimento técnico-cientifico e de suas experiências (SOUTO et al., 2017).

Silveira et al. (2017), no E9, avaliaram o estilo de vida de docentes de uma universidade pública, identificando o bem-estar no trabalho e as alterações em sua saúde. Na identificação da autopercepção dos docentes, realizada através da Escala de Faces de Andrews, obtiveram como resultado predominante na face 2 de "felicidade" o valor de 39\% dos docentes; e a face 1 representou $23 \%$ dos docentes, os quais se autoavaliaram como "extremamente felizes". Em outras palavras, $62 \%$ dos docentes (faces 1 e 2 , as mais representativas entre os docentes) revelaram elevado bem-estar psicológico. Já as faces 3, 4 e 5 representaram $37,8 \%$ dos docentes, os quais apresentaram bem-estar mediano na autoavaliação. Os resultados apontaram que o bem-estar no trabalho e a satisfação relacionam-se com infraestrutura, relações pessoais, lazer no trabalho e carga horária. Os resultados apontam que os docentes apresentaram um alto percentual de felicidade e médio de bem-estar.

O E10 buscou conhecer os aspectos que motivam os docentes da Educação Superior à sua permanência na carreira. Davoglio, Spagnolo e Santos (2017) referiram dez categorias principais que são motivadoras para a permanência dos professores em sua carreira docente: relação com alunos; formação continuada; gosto/ prazer/satisfação pela docência; envolvimento com a pesquisa científica; salário; contribuição social da atuação; ambiente acadêmico, autonomia; segurança/estabilidade/prestígio e desafios/compartilhamento do 
conhecimento. Essas emergiram como aspectos positivos e motivo para a permanência na carreira docente.

\section{Sofrimento no trabalho do professor universitário}

Vivian, Trindade e Vendruscolo (2019), no E2, ao falarem sobre o sofrimento no trabalho dos docentes do ensino superior, atribuem-no a diversos componentes, tais como: a intensificação do trabalho; os limites no reconhecimento profissional; falta de diálogo entre os pares; fragilidades nas relações laborais; intensificação do trabalho com as tecnologias de comunicação; burocratização do trabalho; pressões externas e internas sofridas pelas exigências institucionais de órgãos que fiscalizam e avaliam os seus cursos e às ligadas à organização do trabalho; sobrecarga provocada pelo excesso de demandas, como a alta demanda de produção científica. Referiram que o uso de Tecnologias de Informação e Comunicação (TIC) é ambíguo, pois de um lado trazem prazer por ser um recurso de comunicação, de outro, tencionam a disponibilidade de tempo dos profissionais, pressionando-os para a contínua conectividade, e aumentando-Ihes a carga de trabalho. Atualmente, a tecnologia acaba ocasionando o não distanciamento das atividades laborais, pois demandas vêm frequentemente por WhatsApp ou e-mail mesmo nos finais de semana e em feriados, atrapalhando os momentos de prazer e/ou lazer.

Broch et al. (2020), no E3, apresentado anteriormente na primeira categoria, apontaram que $31,3 \%$ da população investigada, estão em sofrimento no trabalho. Este grupo teve elevada insatisfação em todas as dimensões do constructo avaliadas, com percentuais significativos na integração social e no trabalho e espaço da vida. A insatisfação devido a condições de trabalho e a falta de integração social trazem tensões no cotidiano. Os docentes da IES pública sentem-se insatisfeitos também com as condições estruturais, materiais e de equipamentos que são precários.

No E4, Pena e Remoaldo (2019) relataram que apenas 4\% dos docentes entrevistados revelaram baixo nível de prazer no trabalho. Em relação ao sofrimento, 9\% apresentaram resultados elevados de níveis de sofrimento gerado pelo trabalho. Referiram que isto está relacionado ao estresse e desgaste que a profissão exige, como também dos sentimentos de injustiça, de indignação e do esgotamento emocional no trabalho. Nenhum participante da pesquisa apresentou sintomatologia física ou social devido à atividade docente que tivesse significância. Entretanto, neste trabalho há relatos de sofrimento criativo, o qual os autores referem ser a capacidade de lidar com o sofrimento criando estratégias adaptativas e criativas, sejam individuais ou coletivas. Este tipo de sofrimento relaciona-se a baixo reconhecimento profissional, trazendo insatisfação dos docentes em relação ao seu trabalho (PENA; REMOALDO, 2019).

No E6, os sentimentos de insatisfação também estão relacionados à pouca valorização e reconhecimento da profissão de outros membros da comunidade escolar e esferas gestoras da educação. Em geral, este problema tem afetado a saúde emocional dos professores, pois acreditam que seu trabalho merece reconhecimento (OLIVEIRA; RIBEIRO; AFONSO, 2018). 
No E7, o sofrimento no trabalho é gerado pela insatisfação com as condições de trabalho, já que as universidades públicas federais estão passando, nos últimos anos, por um processo de sucateamento. Referem-se à falta de infraestrutura; sobrecarga de trabalho devido a intensidade de atividades administrativas impostas aos docentes, conflitos interpessoais e mal-estar em relação à condução da gestão. Os autores indicaram que esse sofrimento pode ser minimizado pela mobilização da inteligência prática e da autonomia no contexto laboral do professor universitário. Os docentes utilizam-se do individualismo como uma estratégia defensiva, sendo que também o fazem através de humor e da gratidão, utilizando-os como estratégias mais saudáveis sob o ponto de vista psíquico (AMARAL; BORGES; JUIZ, 2017).

O E8 descreve os sentimentos de prazer e sofrimento no trabalho docente em pós-graduação na perspectiva dos professores ocorrendo ao mesmo tempo. A construção da identidade docente e a visibilidade e reconhecimento são importantes fatores na profissão e o prazer no trabalho é possível quando as pessoas fazem o que gostam e são reconhecidas por isso. Quando há sofrimento, esses estão relacionados à frustação, burocracia, hierarquias e sobrecarga de trabalho (SOUTO et al., 2017). A quantidade de atividades essenciais exigidas do docente pela universidade cria uma sobrecarga de trabalho e gera grande insatisfação, levando muitas vezes ao sofrimento no trabalho. Entretanto, os autores também referiram o sofrimento criativo e quando este ocorre há a transformação de algo ruim em um benefício. Por outro lado, o sofrimento patogênico causa adoecimento psíquico, além de outros fatores como frustração, fracasso, decepção, fadiga, dúvida, desalento e impotência. Neste artigo ficou evidente que a sobrecarga de trabalho gera insatisfação no fazer profissional, interferindo diretamente na saúde desses trabalhadores (SOUTO et al., 2017).

No E9, 85,4\% dos entrevistados afirmaram desenvolver atividades extracurriculares, tendo que levar trabalho para casa a fim de atingir os objetivos propostos. No que se refere a pausas durante a jornada de trabalho $24,7 \%$ não as realizavam, $35,8 \%$ às vezes faziam intervalo; sendo que $67,6 \%$ tiveram pausa de menos de uma hora durante a jornada de trabalho. Mesmo assim, houve pequeno percentual de docentes que se afastaram do trabalho mesmo esta sobrecarga de trabalho causar prejuízos à sua saúde e à sua qualidade de vida.

\section{Prejuízo da saúde física e da saúde psíquica do professor universitário}

No E2, o reconhecimento profissional é considerado como fonte de prazer, entretanto, quando está ausente faz emergir o sofrimento. Entre os achados desta pesquisa, 46,8\% dos docentes identificaram alterações em sua saúde física e emocional. Os danos à saúde foram apontados por fatores relacionados ao cansaço físico, aumento de peso, resultados metabólicos alterados, dores de cabeça e alteração da pressão arterial como consequência de processos de trabalho exaustivos. Ainda consideraram as alterações no sono, preocupação, ansiedade, cansaço como resultado do desajustamento da organização do 
trabalho. Para mediar esses sintomas, usaram algumas medicações para seu alívio. Referiram que a automedicação é comum em professores universitários considerando terem conhecimento mais amplo sobre o assunto em comparação à população em geral, por apresentarem maior autonomia sobre sua própria saúde (VIVIAN; TRINDADE; VENDRUSCOLO, 2019).

Pena e Remoaldo (2019), no E4, em pesquisa com docentes universitários, apontaram que apenas $4 \%$ dos entrevistados tinham baixo nível de prazer no trabalho, 50\% dos docentes apresentaram baixos índices de sofrimento no trabalho e $9 \%$ elevados níveis de sofrimento gerado pelo trabalho, advindos do estresse e do desgaste que a profissão exige, bem como dos sentimentos de injustiça, de indignação e do esgotamento emocional no trabalho e insatisfação. Também encontraram índices muito baixos de sintomatologia associada à atividade laboral. Dos que apresentaram sintomas físicos, salientaram: alterações no sono, dores de cabeça e no corpo.

Tundis e Monteiro (2018), no E5, identificaram fatores críticos do contexto laboral de docentes do ensino superior público da região amazônica associados a riscos à saúde mental. Utilizaram instrumentos para descrever o perfil sociodemográfico e laboral dos sujeitos da pesquisa, como também fizeram uso do Inventário sobre Trabalho e Risco de Adoecimento (ITRA) composto por diferentes escalas que avaliam as dimensões da inter-relação trabalho e riscos de adoecimento. Este instrumento tem enfoque no contexto do trabalho docente universitário, vivências de prazer-sofrimento e danos à saúde. As experiências dos entrevistados também apontaram questões positivas, relacionadas à realização profissional, e negativas, associadas ao esgotamento profissional. A sobrecarga de trabalho tem sido aumentada pelas demandas diversas e pela quantidade de liberações de afastamentos para a realização de pós-graduação, remoções e exonerações, sem haver a suficiente substituição de professores efetivos. Destacaram as disputas profissionais e a falta de integração no ambiente de trabalho como questões que afetam o trabalho, causando desgaste emocional e sofrimento.

As condições de trabalho também foram outro fator apontado, pois são descritas como precárias e insuficientes. Outro fator destacado no estudo foi o fato dos docentes oriundos de outros locais do país apresentarem menos mecanismos protetivos pelo afastamento de familiares e amigos, com prejuízo à saúde evidenciado através dos danos físicos e psicológicos, manifestados por sintomas como dores de cabeça, sentimentos de tristeza, irritação e abandono. As mulheres manifestaram maior insatisfação em relação aos homens. Os autores apontaram que algumas questões foram decisivas para o depoimento dos professores, como um período prolongado de greve de 139 dias das universidades federais, em 2015.

No E2, Silveira et al. (2017) referiram que quando os indicadores como infraestrutura, relações interpessoais, lazer no trabalho e carga horária apresentam deficiências, passam a ser considerados como fatores de adoecimento, causando depressão, estresse e ansiedade. Mesmo mediante uma carga horária extensa, os docentes afirmaram que precisam levar trabalho para 
a sua casa a fim de atingir os objetivos propostos para atender as exigências da instituição. No que se refere às pausas durante a jornada de trabalho $24,7 \%$ não as realizavam e $35,8 \%$ as faziam às vezes. Referente aos espaços para descanso, lazer ou trocas no trabalho, 93,9\% responderam que não existem ambientes apropriados para nenhum tipo de interação, nem com colegas nem com alunos, nem mesmo para fazer uma pausa para lanches no período de trabalho. Também foi relatado que a infraestrutura é precária e insatisfatória.

A atividade docente, e profissional em geral, não é apenas um modo de ganhar a vida, mas é vista como uma forma de inserção social do trabalhador, podendo se constituir em fator de sofrimento, envelhecimento e doenças graves, mas também ser gerador de prazer e desenvolvimento. A percepção de felicidade ou de sofrimento em relação ao trabalho está relacionada à forma como cada um percebe seu cotidiano, ao seu desejo de executar determinadas tarefas e às necessidades do trabalhador (DEJOURS; DÉSSORS; DÉSRIAUX, 1993). Os estudos referidos aqui nesta pesquisa de revisão integrativa apontam que os docentes de instituições de ensino superior têm uma relação ambígua com o seu trabalho. Por um lado, relatam ter prazer no trabalho que realizam, por outro, que ele causa sofrimento e adoecimento, levando-nos a identificar a dicotomia descrita por Marx (1985), originada a partir do capitalismo. O trabalho, inicialmente responsável pela identidade humanizada das pessoas em relação ao mundo selvagem, com o surgimento do capitalismo passou a ser fonte de sofrimento e desvalorização humana. No primeiro caso, há espaço para prazer e realização, enquanto no segundo isso parece impossível.

Quando os professores referiram ser o trabalho docente causador de sofrimento, apontaram questões como a sobrecarga de trabalho, a falta de reconhecimento das atividades que realizam, o excesso de burocracia, a falta de infraestrutura, dentre outras. Para minimizar este mal-estar em relação às questões levantadas acima, Codo (1998) aponta que o trabalho que traz significado é objeto de motivação e de prazer. Quando isso não acontece, os docentes acabaram relatando falta de sono, depressão e estresse, fatores que afetam sua saúde. Para driblar esses sintomas, recorrem à automedicação.

Quando os efeitos do trabalho são positivos, ele pode se constituir em fonte de felicidade, satisfação e bem-estar. Freud (1975) afirma que quando se escolhe livremente uma atividade produtiva, ela gera prazer e satisfação. Assim, o local de trabalho pode se transformar em lugar de realizações, valorização profissional e reconhecimento. Nos estudos levantados aqui, foi apontado pelos docentes que uma das questões que leva ao sofrimento do trabalho é a falta de reconhecimento profissional. Quando a realidade de trabalho é restritiva, gera conflitos e sofrimento. Em função disso, é fundamental que os gestores das IES possam observar a forma como o trabalho é organizado e possibilitar que os docentes possam se sentir partícipes, pois quando há liberdade de expressão e de opiniões, o grau de satisfação com ele aumenta e o trabalhador trabalha com mais disposição (FREUD, 1975).

Estudo realizado em 2014 apontou que a grande maioria dos docentes referiu se sentir feliz com o trabalho que realizam e salientaram fatores que 
contribuíram para a sua felicidade: relações interpessoais, relacionamento positivo com professores, coordenações e alunos, que oferecem apoio social, técnico e emocional no cotidiano de trabalho, reduzindo sentimentos de solidão e frustação. De certa forma, esses aspectos também foram referidos nos estudos analisados aqui neste estudo. Dejours (2015) refere que o mundo do trabalho sofre de solidão e sofrimento quando a relação homem/organização fica bloqueada, ou seja, quando o trabalhador não percebe reciprocidade por parte de seus colegas e coordenações.

Em relação à sensação de felicidade no trabalho, Macey e Schneider (2008) consideram-na como um estado psicológico positivo do indivíduo cujo comportamento é influenciado e pode desenvolver ações positivas para si e para as organizações. Para Farcen et al. (2018), o trabalho é um incentivador da felicidade e um agente promotor da saúde quando respaldado por princípio éticos e respeito. Torna-se central na medida em que oportuniza ao trabalhador as condições que proporcionam o desenvolvimento da autoestima, do autoconceito, de realização, de crescimento, sendo fonte de satisfação, qualidade de vida, bem-estar e felicidade. A percepção de felicidade é um preditor de qualidade de vida relevante, já que descreve a experiência interna de cada sujeito, sendo uma ferramenta que auxiliará na elaboração de estratégias organizacionais para a promoção da saúde, prevenção de doenças, planejamento e desenvolvimento de ações interdisciplinares que motivem os trabalhadores (FERRAZ; TAVARES; ZILBERMAN, 2007; SATUF; REIS, 2017).

Como fatores negativos, este estudo de 2014 apontou alguns fatores considerados insatisfatórios pela maioria dos docentes: diversidade de tarefas, pouco grau de autonomia na realização do trabalho, exigências de habilidades e concentração, retorno e possibilidade de controle das situações, nível de interesse dos alunos, imagem interna e externa da IES, aprimoramento e desenvolvimento profissional, tempo para lazer e para a família, salário, jornada de trabalho, apoio socioemocional, estado geral de tensão/estresse e qualidade de vida global (REBOLO; BUENO, 2014).

Foi salientada pelos estudos analisados a precarização do trabalho, não somente em relação a infraestrutura, mas também nas condições de formação e trabalho docente e organização do ensino. Esta organização impõe exigências de trabalho que geram sobrecarga para o trabalhador. Para Dejours (2012), transformar um trabalho fatigante em equilibrante e prazeroso é necessário, mas para isso as organizações precisam ser flexíveis. A falta de reconhecimento é outra questão que necessita de atenção das organizações, pois ela gera sentimentos de injustiça, desconforto, desvalorização e, com isso, os trabalhadores ficam desmotivados ao trabalho. O trabalho docente necessita de professores motivados e capacitados, atualizando-se constantemente para atender às demandas da sociedade. Entretanto, se o professor se sentir em sofrimento com o seu trabalho isso não acontece, prejudicando todo o processo de ensino-aprendizagem. As consequências físicas, sociais e psicológicas são grandes quando isso ocorre (MENDES; FERREIRA, 2007). As doenças relacionadas ao trabalho são numerosas entre docentes. A falta de iluminação, mobiliário adequado, condições acústicas afetam a saúde do professor até 
mesmo sem ele perceber, trazendo como consequências problemas de voz, na coluna, dores musculares e distúrbios visuais (PITA, 2010). O primeiro grupo de problemas apontados pela autora relaciona-se à infraestrutura e foi referido pela grande maioria dos estudos encontrados nesta revisão. Por outro lado, problemas na voz, na visão e na coluna não foram referidos. Entende-se que esses afetam a vida dos professores a longo prazo e nem sempre eles associam esses problemas à sua prática docente.

\section{Considerações finais}

Esse estudo buscou conhecimentos acerca do trabalho docente de instituições de ensino superior, investigando a percepção dos docentes sobre felicidade e sofrimento no trabalho. O objetivo proposto foi atendido, pois foram descritos os principais aspectos relacionados ao bem-estar e à felicidade dos professores do ensino superior, o sofrimento no trabalho e sua influência na saúde no professor. Assim, os achados deste estudo responderam a sua pergunta norteadora "Qual a influência do trabalho docente na percepção dos professores sobre felicidade e sofrimento no trabalho?".

A amostra final desta pesquisa foi composta por dez estudos selecionados pelos critérios de inclusão. Emergiram três categorias para a apresentação dos resultados, que são: felicidade no trabalho do professor universitário, o sofrimento no trabalho do professor universitário e prejuízo da saúde física e da saúde psíquica do professor universitário.

Nove estudos (90\%) discutiram a questão da felicidade no trabalho do professor universitário, esclarecendo aspectos importantes que vieram a corroborar com a autora desta pesquisa em entender se há presença de felicidade, bem-estar ou prazer no docente universitário. Dos sete estudos (70\%) que apresentam dados sobre o sofrimento no trabalho do professor universitário, todos mostraram o quanto o meio docente pode apresentar falta de felicidade no exercício laboral do docente de ensino superior, podendo sua percepção flutuar entre felicidade e sofrimento, de acordo com variáveis externas ou internas do trabalho docente e com o momento da vida deste profissional. Da terceira categoria, quatro estudos (40\%) apontaram a ocorrência de prejuízo da saúde física e da saúde psíquica do professor universitário, em menor número comparando-se às duas categorias anteriores. Considerando que as situações que desenvolveram foram doenças biopsicossociais, essas têm uma significância imensurável neste universo da IES, porque podem ter a característica de alterações temporárias ou de adquirirem aspectos de cronicidade, levando alguns a afastamentos laborais. Além disso, um professor comprometido emocionalmente pode colocar em risco o processo ensino-aprendizagem

Considerando os aspectos apontados, sugere-se realizar novos estudos a fim de identificar e contextualizar as características dos docentes no ambiente de universidades, levantar as questões da felicidade no trabalho e seus prováveis impactos no comportamento do indivíduo na organização, na qualidade de vida e do bem-estar. Imagina-se que as condições e sobrecarga de 
trabalho devam ter piorado bastante em função da Pandemia da Covid-19, com o trabalho em Home Office, portanto, este é um tema que deve ser ainda investigado já que os professores se encontram há mais de ano trabalhando em suas casas, o que possivelmente traz uma série nova de dificuldades relacionadas ao trabalho.

\section{REFERÊNCIAS}

ALBUQUERQUE, Anelise Salazar; TRÓCCOLI, Bartholomeu Tôrres. Desenvolvimento de uma escala de bem-estar subjetivo. Psic.: Teor. e Pesq., Brasília, v. 20, n. 2, p. 153-164, 2004.

AMARAL, Graziele Alves; BORGES, Amanda Leal; JUIZ, Ana Paula de Melo. Organização do trabalho, prazer e sofrimento de docentes públicos federais.

Cadernos de Psicologia Social do Trabalho, vol. 20, n. 1, p.15-28, 2017.

BROCH, Caroline et al. A satisfação no trabalho docente em educação física: um diagnóstico do perfil de professores universitários. J. Phys. Educ. v. 31, e3179, Maringá, 2020.

CODO, Wanderley; SAMPAIO, José Jackson Coelho; HITOMI, Alberto Haruyoshi. Indivíduo, Trabalho e Sofrimento: uma abordagem interdisciplinar. 3 ed. Petrópolis, RJ: Vozes, 1998.

DAVOGLIO, Tárcia Rita; SPAGNOLO, Carla; SANTOS, Bettina Steren dos. Motivação para a permanência na profissão: a percepção dos docentes universitários. Psicologia Escolar e Educacional, SP. v. 21, n.2, p. 175-182, 2017.

DEJOURS, Christophe. A loucura do trabalho: estudo de psicopatologia do trabalho. 6 ed. São Paulo: Cortez Oboré, 2015.

DEJOURS, Christophe. Psicodinâmica do trabalho e teoria da sedução. Psicologia em Estudo, Maringá, v. 17, n. 3, p. 363-371, 2012.

DEJOURS, Christophe; DÉSSORS, Dominique; DÉSRIAUX, François. Por um trabalho, fator de equilíbrio. Revista de Administração de Empresas, v.33, n.3, 98-14, 1993.

FARSEN, Thaís Cristine et al. Qualidade de Vida, Bem-estar e Felicidade: sinônimos ou conceitos que se diferenciam. Interação em Psicologia, v.22, n.1, p.31-41, 2018.

FERRAZ, Renata Barboza; TAVARES, Hermano; ZILBERMAN, Monica L.

Felicidade: uma revisão. Rev. Psiq. Clínica, v.34, n.55, p.234-242, 2007. 
FREUD, Sigmund. Além do principio de prazer [1920]. In: Edição Standard brasileira das obras psicológicas completas de Sigmund Freud. Vol. XVIII. Rio de Janeiro: Imago, 1975.

GALVÃO, Cristina Maria; SAWADA, Namie Okine; TREVIZAN, Maria Auxiliadora. Revisão sistemática: recurso que proporciona a incorporação das evidências na prática da enfermagem. Rev Latino-Am Enferm., v.12, n.3, p. 549-556, 2004.

GONÇALVES, Josiane Peres. Bem-Estar Subjetivo, Bem-Estar Psicológico e BemEstar Social e Sua Relação Com o Bem-Estar dos Professores. I Simpósio Nacional de Educação da Unioeste Cascavel. Anais... Cascavel PR, Unioeste, 2008.

HOUAISS, Antonio. Novo Dicionário Houaiss da Língua Portuguesa. 1 ed. Rio de Janeiro: Objetiva, 2014.

MACEY, William H.; SCHNEIDER, Benjamin. The meaning of employee engagement. Industrial and Organizational Psychology, v.1, n.1, p. 3-30, 2008.

MARX, Kall. O Capital: crítica da economia política. São Paulo: Abril Cultural, 1985.

MENDES, Ana Magnólia; FERREIRA, Mário César. Inventário sobre Trabalho e Riscos de Adoecimento - ITRA: instrumento auxiliar de diagnóstico de indicadores críticos no trabalho. In: MENDES, Ana Magnólia (Org.),

Psicodinâmica do trabalho: teoria, método e pesquisas. São Paulo: Casa do Psicólogo, 2007. p. 111-125.

MENDES, Karina; SILVEIRA, Renata Cristina; GALVÃO, Cristina. Revisão integrativa: método de pesquisa para a incorporação de evidências na saúde e na enfermagem. Texto Contexto Enferm., v.17, n.4, p. 758-764, 2008.

MENDONÇA, Alethea Deyze. Felicidade no ambiente de trabalho: realidade ou utopia? 2016. 117f. Dissertação (Mestrado em Promoção de Saúde e Prevenção da Violência). Faculdade de Medicina. Universidade Federal de Minas Gerais, Belo Horizonte, 2016.

MENDONÇA, Alethea Deyze; JUNGES, José Roque; PINHEIRO, Tarcísio Márcio Magalhães. Felicidade, saúde e ética no ambiente de trabalho. Rev.Med.Minas Gerais, v.26, supl 8, p. 185-190, 2016.

NEVES, Diana Rebello; NASCIMENTO, Rejane Prevot; FELIX JR, Mauro Sergio; SILVA, Fabiano Arruda da Rui; ANDRADE, Otávio Bernardes de. Sentido e significado do trabalho: uma análise dos artigos publicados em periódicos associados à Scientific Periodicals Electronic Library. Cad. EBAPE.BR, v. 16, n. 2, p. 318-330, 2018. 
OLIVEIRA, Ivan Bremm; RIBEIRO, José Antonio Bicca; AFONSO, Mariangela da Rosa. Satisfação com a profissão: um estudo com professores de educação física. Pensar a Prática, v. 21, n. 1, p. 82-95, 2018.

PENA, Liliane; REMOALDO, Paula. Psicodinâmica do Trabalho: um estudo sobre o prazer e o sofrimento no trabalho docente na Universidade Óscar Ribas.

Saúde Soc. São Paulo, v.28, n.4, p.147-159, 2019.

PITA, Marina. Estresse laboral, assédio moral e burnout marcam produtivismo. Revista Adusp, n. 48, p. 14-21, 2010.

REBOLO, Flavinês; BUENO, Belmira Oliveira. O bem-estar docente: limites e possibilidades para a felicidade do professor no trabalho. Acta Scientiarum Education. Maringá, v. 36, n. 2, p. 323-331, 2014.

RIBEIRO, Andresa Daroci Silva; SILVA, Narbal. Sentido e significado de felicidade no trabalho para professores. Navus, Florianópolis, v. 10, p 01-19. 2020.

RIBEIRO, Carlos Antonio Costa. Renda, Relações Sociais e Felicidade no Brasil. Dados - Revista de Ciências Sociais, v. 58, n. 1, p. 37-78, 2015.

SATUF, Cibele; REIS, Inês Pires dos. Satisfação laboral e felicidade: um estudo comparativo entre portugueses e brasileiros. Revista Psicologia:

Organizações e Trabalho, v.17, n.4, p. 201-209, 2017.

SCREMIN, Greice; ISAIA, Silvia Maria de Aguiar. Docência no ensino superior: o papel dos docentes nos cursos de licenciatura. XI Congresso Nacional de Educação, PUC do Paraná, Curitiba. EDUCERE, 2013.

SENDER, Gisela; FLECK, Denise. As Organizações e a Felicidade no Trabalho: Uma Perspectiva Integrada. RAC, Rio de Janeiro, v. 21, n. 6, p. 764-787, 2017.

SILVEIRA, Renata Cristina da Penha et al. Bem-estar e saúde de docentes em instituição pública de ensino. Rev. Enferm. UFPE, v.11, supl.3, p.1481-1488, 2017.

SOUTO, Bruna Lecintia Carpes et al. O trabalho docente em pós-graduação: prazer e sofrimento. Rev. Enferm. UFSM, v.7, n.1, p. 29-39, 2017.

TUNDIS, Amanda Gabriela Oliveira; MONTEIRO, Janine Kieling. Ensino superior e adoecimento docente: um estudo em uma universidade pública. Psicol. educ., n.46, p. 1-10, 2018.

VASCONCELOS, Anselmo Ferreira. Felicidade no ambiente de trabalho: exame e proposição de algumas variáveis críticas. REAd, v. 10, n. 1, p. 1-18, 2004. 
VIVIAN, Chancarlyne; TRINDADE, Letícia de Lima; VENDRUSCOLO, Carine. Prazer e sofrimento docente: estudo na pós-graduação stricto sensu organizacional. Revista Psicologia: Organizações e Trabalho, v.20, n.3, p. 1064-1071, 2020.

ZABALZA, Miguel Angel. O ensino universitário: seu cenário e seus protagonistas. Porto Alegre: Artmed, 2004. Aceito em: 22 de novembro de 2021. Publicado em: 05 de janeiro de 2022. 